\title{
Külttürel Jeoloji Açısından Hasankeyf (Batman) Yerleşmesi
}

\author{
Hasankeyf (Batman) Site From Cultural Geological Perspective
}

\section{Derya SINAANOĞLU ${ }^{1}$, Muzaffer SIIYAKO ${ }^{2}$, Sabri KARADOĞAN ${ }^{3}$, Nazire ÖZGEN ERDEM ${ }^{4}$}

'Batman Üniversitesi, Jeoloji Müh.Bölümü, Batman (derya.sinanoglu@batman.edu.tr)

${ }^{2}$ Türkiye Petrolleri A.O. Arama Dairesi Başkanlığı, Ankara

${ }^{3}$ Dicle Üniversitesi, Ziya Gökalp Ë̆itim Fakültesi, Diyarbakır

${ }^{4}$ Cumhuriyet Üniversitesi, Jeoloji Müh. Bölümü, Sivas

\section{ÖZ}

Batman'ın bir ilçesi olan Hasankeyf; günümüzde önemini yitirmiş olsa da geçmişinde bölgenin önemli bir bilim ve kültür merkezi olarak pek çok medeniyeti bünyesinde barındırmıştır. Dicle Nehri kenarında yer alan Hasankeyf, kayalara oyulmuş yüzlerce yerleşme biriminden oluşmaktadır. Bir sit alanı olan Hasankeyf'in özgün değeri, jeolojik ve jeomorfolojik yapının zamanın şartlarına uygun olarak akıllıca kullanımından kaynaklanır. Öncelikle bölgenin savunma fonksiyonunun ön planda olduğu bir yerleşmedir. Öte yandan, binlerce nüfusu barındırabilecek kaya oyuğu meskenlerden ve karmaşık yerleşim birimlerden oluşmaktadır. Böylesine akıllıca ve organize bir kaya kentinin oluşumunda en önemli faktör, jeomorfolojik yapının yanı sıra kuşkusuz kaya özellikleridir. Bir kaya kentinin görkemli görüntüsü, çevresindeki jeolojikjeomorfolojik unsurların zenginliği ve yerleşmenin sürekliliğine etkisi, Hasankeyf'in özgün bir kültürel jeolojik miras olarak ele alınması ve değerlendirilmesini gerektirmektedir.

Anahtar Kelimeler: Batman, Hasankeyf, Kültürel Jeoloji, Jeomorfoloji

\section{ABSTRACT}

Hasankeyf, a district of Batman, is positioned near Tigris river, assigned as protected area and consists hundreds of residents which are located in carved rocks. Although, Hasankeyf has lost its importance today, it was containing many civilizations, culture and knowledge in the region before. Hasankeyf is unique since, geologic and geomorphologic structure has been used wisely in accordance with today's conditions. Firstly, defense of the premises had a crucial role while Hasankeyf had been shaped. Carved rocks in there, sheltered thousands of people within a complex organization. Not only the geomorphologic 
structure, but also the characteristics of rocks have an effect on the generation of carved rock settlements. Hasankeyf should be considered as a cultural geologic heritage owing to, the magnificent appearance of carved rock settlements, the richness of geologic-geomorphologic elements and their effects on the settlement's continuity.

Keywords: Batman,Cultural Geology, Geomorphology, Hasankeyf

\section{GİIŞ}

Tarihi Hasankeyf yerleşmesi coğrafi olarak Güneydoğu Anadolu Bölgesi'nin Dicle Bölümü'nde, Batman il sinırları içerisindedir (Şekil 1). Bu bölge, Türkiye'nin genç tektonik birliklerinden kenar kıvrımları kuşağı üzerinde, Arap Plakası'nın kuzey ucunda yer alır. Batman'ın kuzey kesimlerinde kalan asıl bindirme kuşağına göre çalışma alanında çok daha geniş ve yayvan kıvrımlanmış yapılar görülür. Bu nedenle oluşmuş düşük engebeleriyle de dikkat çeken saha, çok kıvrımlı kırıklı ve şaryajlı kuzeydeki dağlık alanlardan daha kolay ayırt edilebilen morfolojik bir özelliğe sahiptir.

Antik yerleşme, Diyarbakır havzasının doğusunda, Dicle Nehri’nin havza düzlüklerinden dağlık kütle içerisine girdiği, Raman ve Softek antiklinalleri arasında yer alır (Şekil 2). Dicle Nehri burada dar bir senklinalin içerisinden akmaktadır. Aslında "Hısnkeyfa" olan bu eski yerleşim yerinin adı "Kaya Hisarı" şeklinde tercüme edilir. Eski tarih ve kavimlerde bu kelimenin "korunmaya müsait" yer anlamına geldiği de belirtilmektedir. Kalenin yekpare taş üzerine kurulmuş olması nedeniyle "Taş Kalesi”" olarak da anılmıştır.

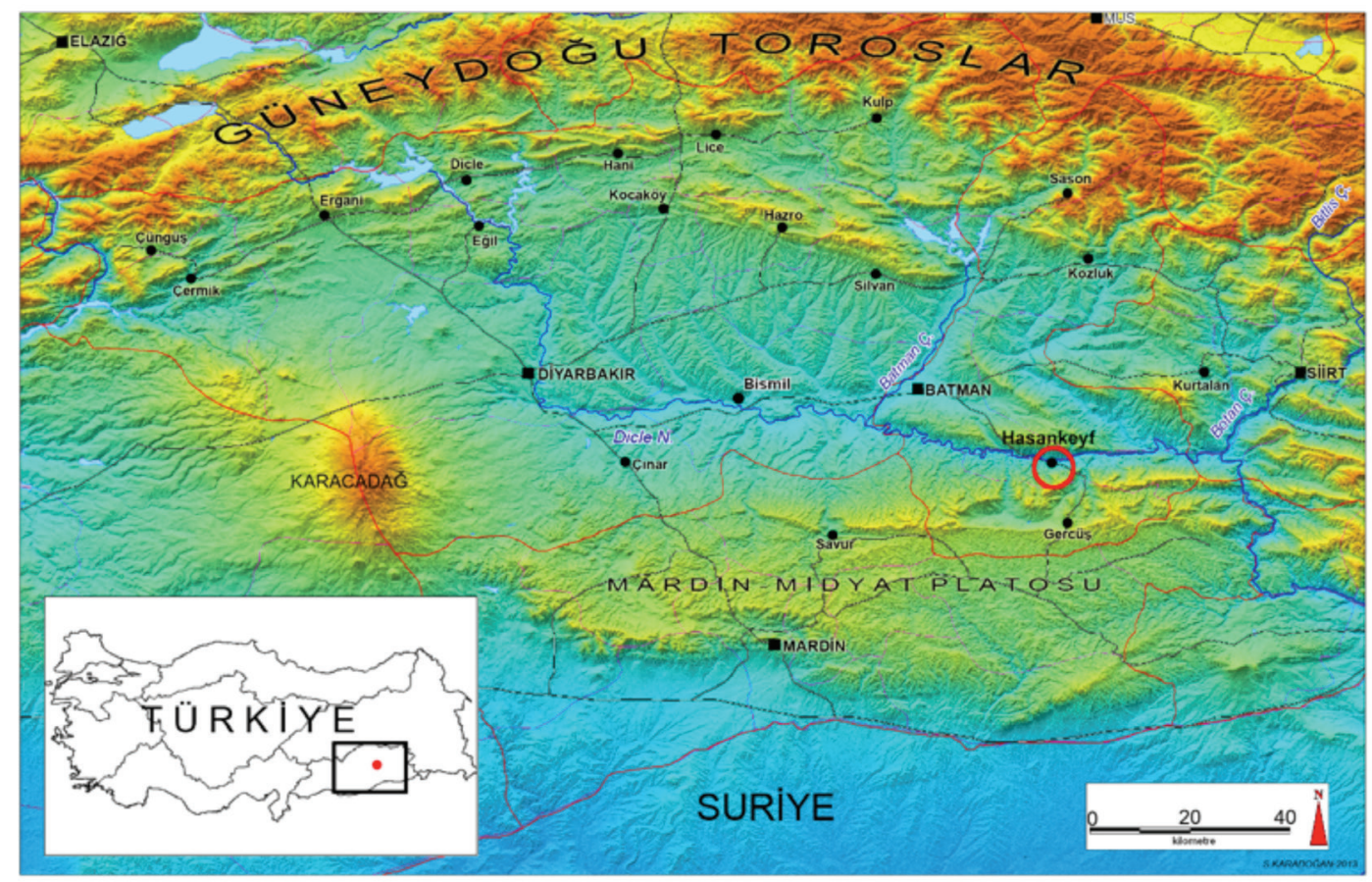

Şekil 1. Çalışma alanının lokasyon haritası.

Figure 1. Location map of the study area. 
Çalışma sahası, içerisinde Hasankeyf antik kentinin olmasının yanı sıra, Raman Dağı'nda Türkiye'nin en zengin petrol yataklarının bulunması ve üretilmesi nedeniyle, yerli ve yabancı bilim adamlarının jeoloji, arkeoloji, tarih ve coğrafya açısından çok eski yıllardan beri ilgisini çekmektedir (Yıldırım ve Karadoğan, 2005). Ayrıca Dicle Nehri üzerine yapılan Ilısu Baraj1 ve Hidroelektrik Santrali nedeniyle, tarihi Hasankeyf kentinin bir bölümünün baraj suları altında kalma riskine sahip olması, yurtiçi ve yurtdışı kamuoyunun dikkatini bu sahaya çekmiştir.

\section{JEOLOJi}

Güneydoğu Anadolu Bölgesi jeolojisinin ana yapısını, Arap ve Anadolu kitalarının zaman boyutu içerisinde göreceli hareketleri kontrol etmiş, bölgedeki temel yapısal unsurlar son şeklini Miyosen döneminde almıştır. Kuzey güney yönlü sıkışma rejiminin etkisiyle, genel olarak doğubatı eksenli asimetrik antiklinal ve senklinaller gelişmiş olup, çalışma alanında hidrokarbon bakımından da ekonomik olan en büyük yapı olan Raman Antiklinali, Hasankeyf'in kuzeyinde, Softek Antiklinali ise güneyinde yer almaktadır. Bu iki antiklinal arasındaki dar senklinal ise Dicle Nehri'nin alüvyon ovasından geçmektedir (Şekil 2).

Bölgedeki sıkışma rejimine bağlı olarak Arap Kıtası üzerindeki alçalıp yükselmeler, sedimantasyonu büyük ölçüde etkilemiştir. $\mathrm{Bu}$ nedenle birimler arasında bölgesel ölçekte yanal giriklikler de gözlenmektedir. Hasankeyf çevresinde Paleosen'den başlayarak günümüze kadar gelen zaman aralığında çeşitli fasiyeslerde oluşmuş kayalar mostra vermektedir (Şekil 2 ve 3).
En altta Paleosen yaşl1; denizel ortamda çökelmiş kumtaşı katkılı şeyl ve marnlardan oluşan ve kalınlığ 700 metreye kadar ulaşan Germav Formasyonu (Maxon, 1937) yer alır. Bu birim üste doğru regresif bir özellik kazanır ve kumtaşı oranı artarak karasal fasiyeslere geçer. Üst Paleosen yaşlı bu karasal fasiyesler, Antak Formasyonu olarak adlandırılan birimin (Koaster, 1963) eşiti olarak kabul edilmiş olup (Siyako vd., 2013; Bahtiyar vd., 2015) çamurtaşı, kumtaşı ve çakıltaşlarından oluşmaktadır. Genellikle akarsu ortamını temsil eden birim içerisinde yer yer gölsel karbonatlar da bulunmakta ve birimin kalınlığ 1 350 metreye kadar çıkmaktadır.

Antak Formasyonu'nun çökeliminden sonra bölge yükselerek aşınmış ve Orta Eosen'den itibaren yeni bir transgresyon gelişmiştir. $\mathrm{Bu}$ transgresyonun ilk ürünü olan taban klastikleri, her yerde haritalanabilecek kalınlıkta olmayıp Maxon (1937) tarafından adlanan Gercüş Formasyonu'na dahil edilmiştir (Siyako vd., 2013; Bahtiyar vd., 2015). Birimin kalınlığı 30 metreye kadar ulaşabilmektedir. Daha üstte bölgede geniş yayılımı olan ve dolomitik kireçtaşlarından oluşan Hoya Formasyonu (Perinçek, 1978) görülür. Kalınlığg 400 metreye ulaşan birimin üst seviyelerinde evaporit katkılı tebeşirli kireçtaşı ve dolomitler gelişmiştir. Bir kısmı doğal mağara olan Hasankeyf' in tarihi kaya evleri bu son seviyelerde oyulmuştur. Bu nedenle, Hoya Formasyonu'nun alt seviyelerinden kolaylıkla ayrılabilen bu birim, aynı formasyon içerisinde Hasankeyf üyesi olarak adlandırılmış ve haritalanmıştır (Siyako vd., 2015). Bu birim harita alanının kuzey ve doğusunda Germik Formasyonu (Bolgi, 1961) olarak tanımlanan ve büyük oranda evaporitlerden oluşan birime dereceli olarak geçmektedir. Burada Hasankeyf üyesi olarak tariflenen birim 
de eski haritalarda Germik Formasyonu'na dahil edilmiştir. Aslında Hasankeyf birimi, Hoya ile Germik formasyonları arasındaki geçiş fasiyesini oluşturmaktadir.

Çalışma alanında stratigrafik olarak en üste, 100-500 metre kalınlığında Miyosen yaşlı flüviyal çamurtaşı, çakııltaşı ve kumtaşlarından oluşan Şelmo Formasyonu (Bolgi, 1961) yüzeylenmekte, onun üzerine ise Dicle Nehri ve kollarının biriktirdiği alüvyonlar gelmektedir.

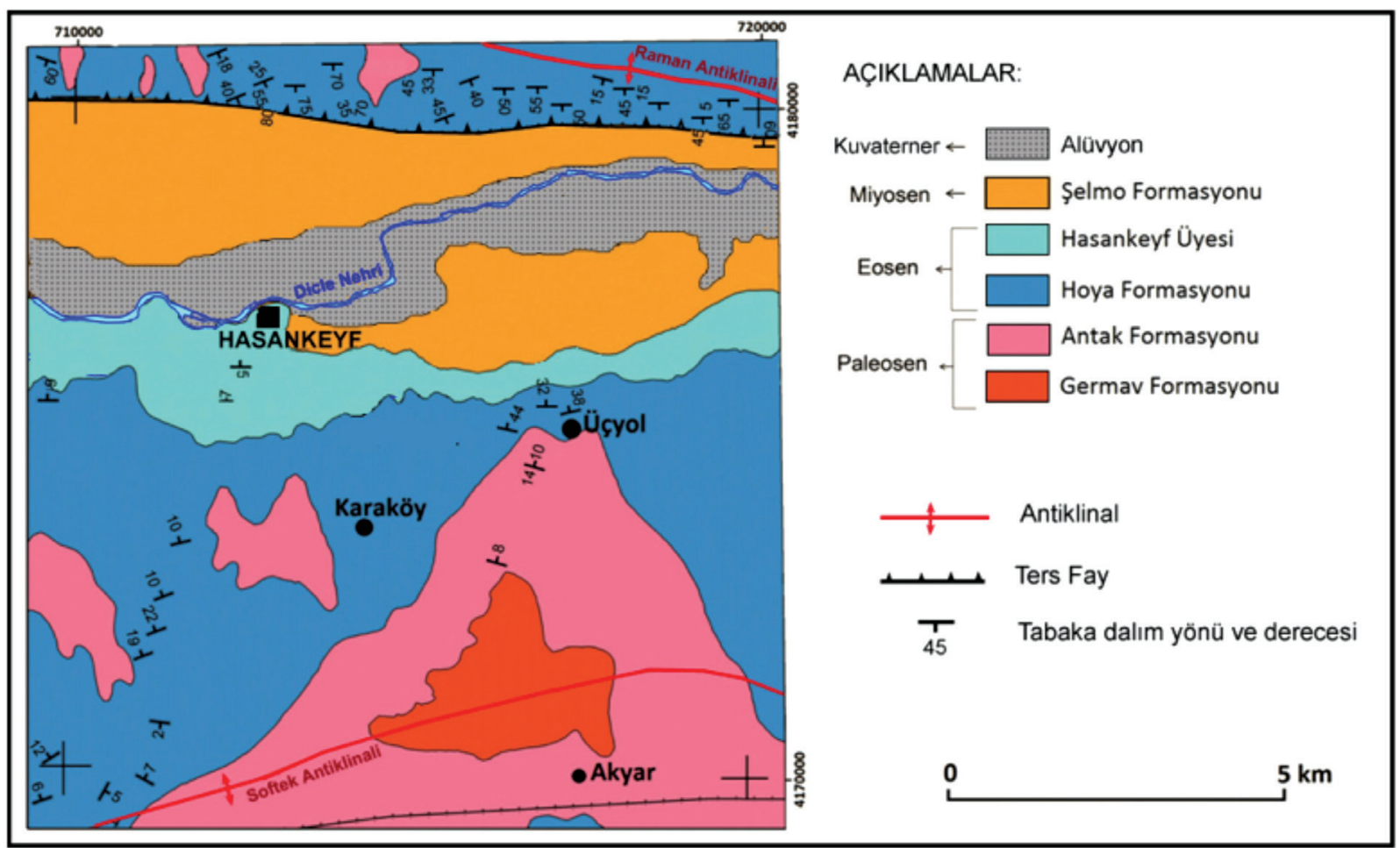

Şekil 2. Çalışma alanının jeoloji haritası (Siyako vd., 2015'ten değiştirilerek alınmıştır).

Figure 2. Geological map of the study area (Modified from Siyako et al., 2015).

\section{JEOMORFOLOJI}

Tektonizma etkisiyle gelişen kıvrımlı yapılar, yatay tabakalar, karstlaşma, fluviyal süreçler gibi yapısal ve morfojenetik birçok faktör ve süreç tarafindan şekillenen Hasankeyf ve çevresinde bu bölgeye özgü çok çeşitli ve zengin bir rölyef oluşmuştur (Fay rölyefi, kıvrımlı yapı rölyefi, yatay ve monoklinal yapı rölyefi, akarsu topoğrafyasına ait elemanlar, karstik şekiller). Bu nedenle çok farklı alanlarda görülebilecek birçok yer şeklini aynı saha içinde yan yana ve iç içe geçmiş durumda gözlemlemek mümkündür (Şekil 4 ve 5).

\section{Yapısal şekiller}

Tektonik jeomorfoloji, fayl ve kirlkl yapılar: Bölge tektonik açıdan aktif bir zonda yer alır ve genç tektonizmaya ait jeolojik-jeomorfolojik şekiller Dicle Nehri vadisinin her iki yakasında fay aynaları, fay façetaları (üçgen sırtlar), balık sırtı şeklinde sırtlar ve bindirme yapılarına özgü 


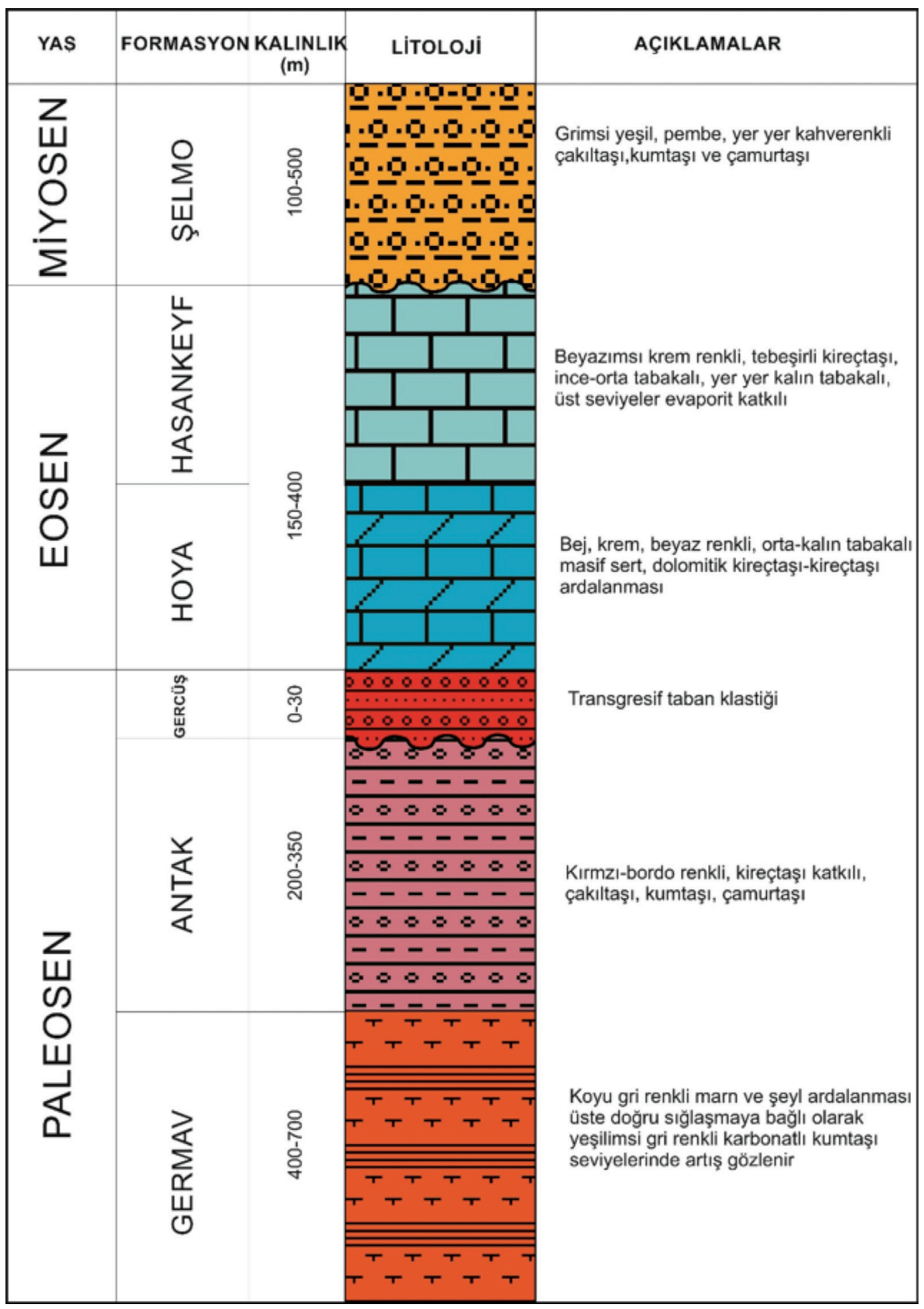

Şekil 3. Çalışma alanı genelleştirilmiş stratigrafi kesiti (Siyako vd., 2015'ten değiştirilerek alınmıştır). Figure 3. Generalized stratigraphic section of the study area (Modified from Siyako et al., 2015). 
yer şekilleri sıkça görülür. Özellikle Raman Dağı'nın güneyini sınırlayan Raman Fayı ve bu faya bağlı olarak oluşmuş fay yamaçları, dönmüş ve bindirmiş kıvrımlar, üçgen sırtlar, asılı genç vadiler, tipik şekillerdir (Yıldırım ve Karadoğan, 2011).

Yatay ve Monoklinal yapı şekilleri: Hoya Formasyonu'nun üst kesimlerini oluşturan birimler kimi yerde yatay ve yataya yakın, kimi yerde ise kuzeye doğru eğimli tabaka özellikleri göstermektedir. Bu nedenle Dicle Nehri'nin güney kesimlerinde yatay ve monoklinal yapı şekilleri ortaya çıkmıştır. Dicle Nehri'ne özellikle güneyden kavuşan vadilerde ana nehrin gömülmesine bağlı olarak şiddetli bir yarılma meydana gelmiş, sonuçta yamaçlarında şev ve basamakların dönemlik şelale izleri ve dev kazanlarının, büt ve mesa gibi yapısal konik tepelerin, kule karstı benzeri şekillerin dikkati çektiği dar ve derin kanyon vadiler, sübsekant depresyonlar, boğaz ve kluz tipi vadiler oluşmuştur (Şekil 4 ve 5).

\section{Fluviyal şekiller}

Dicle Nehri'ne bağlı olarak akarsu aşındırma ve biriktirme süreçleri önemli bir jeomorfolojik faktördür. Tektonik aktivitelere bağlı olarak (Anadolu karasının yükselmesi) Dicle Nehri’nin menderesli akış düzeninin olduğu gibi temele gömülmesi ile menderesli gömük vadi ve buna bağlı olarak birçok yerde nisbi yükseltisi 100 metreye varan adeta duvar gibi yamaçlar oluşmuştur. Bu yamaçlarda da Dicle Nehri'nin gömülmesine ayak uyduramayan kimi vadiler ender rastlanan asıl1 vadiler meydana getirmiştir. Hem karalarda meydana gelen toptan yükselme olayı hem de Kuvaterner buzul dönemlerinde yaşanan akarsu gömülmesine bağlı olarak Dicle
Nehri'ne kavuşan kollarda derin gömülmeler gelişmiştir. Hasankeyf, Dicle Nehri'ne kavuşan akarsular tarafından derince yarılmış, korunmaya elverişli basamaklar şeklindeki düzlükler üzerinde kurulmuştur. Hasankeyf yerleşiminin de içinde bulunduğu Dicle vadisinde meydana gelen diğer bir önemli jeomorfolojik olay, nehir yatağında meydana gelen homoklinal kaymadır. Güneyi ters faylı Raman Dağı yükselimine bağlı olarak Dicle Nehri sürekli olarak güneye kaymış ve güney yamaçlarını daha fazla aşındırarak sarp yamaçların oluşumunda etkili olmuştur. Vadi yamaçlarında nehrin gömülme dönemlerine işaret eden basamaklara ve polisiklik anakaya taraçaları oluşmuştur. Söz konusu fluviyal aşınım şekilleri dışında Hasankeyf çevresinde rastlanan diğer fluviyal şekiller; alüvyal dolgu taraçaları, birikinti yelpazeleri ve Raman Dağı güneyindeki dağ eteği ovas1, Dicle Nehri yatağındaki kum adaları, dev kazanı şekilleri olarak sıralanabilir (Şekil 4).

\section{Karstik şekiller}

Hasankeyf çevresinde diğer önemli bir morfojenetik faktör karstlaşmadır. Zira sahada tanımlanan formasyonlar çoğunlukla jips, anhidrit, kireçtaşı ve dolomit gibi çözünebilir kayalardan meydana gelmektedir. Bu kayaçların karbonik asitli yağmur sularıyla çözünmesi, yine çözünen ve sulardaki eriyik halde bulunan çözelti maddelerin uygun koşullarda birikmesiyle ifade edebileceğimiz karstik süreçler ve bu süreçler sonucu oluşan yer şekillerine rastlanır. Karbonatlı litolojinin görüldüğü yerlerde çözünmeye bağlı olarak lapyalar, kaya oyukları, şahit ve mantar kayalar, kanyon vadiler gibi aşınım şekilleri oldukça yaygındır.

Sahadaki diğer bir karstik oluşum süreci bölgede çok yaygın olan ancak daha çok diğer 
formasyonlarla örtülü halde bulunan ve özellikle yer altı suyuyla gelişen jips karstıdır. Ancak mostra veren birimler üzerinde gelişen görünür yüzey karstı şekilleri uzun ömürlü değillerdir.
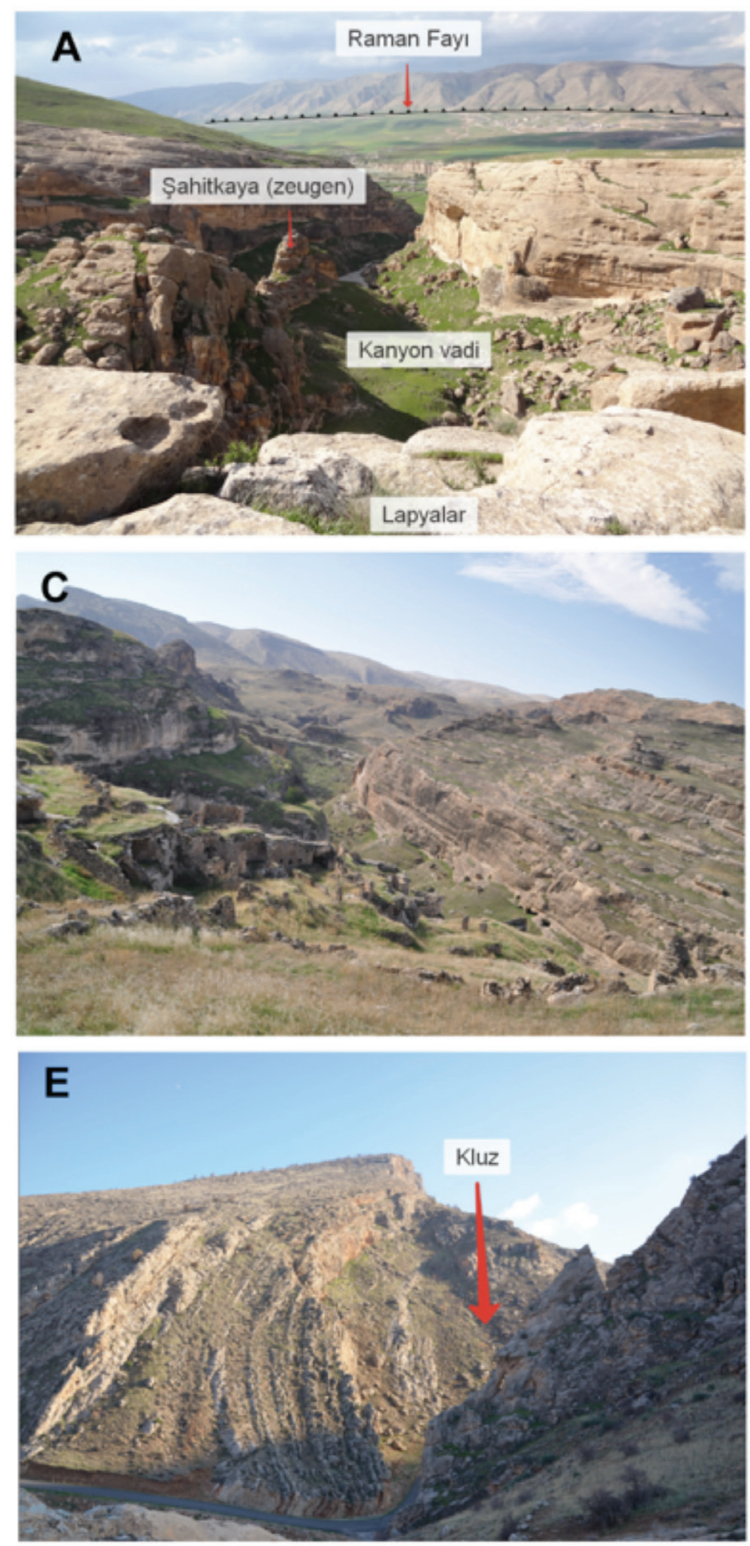

Karstik süreçler içinde sahada dikkati çeken diğer jeomorfolojik olaylar; nemli ve sıcak iklim dönemlerinde birikime bağlı olarak meydana gelmiş traverten ve kalsit kabuk oluşumlarıdır.
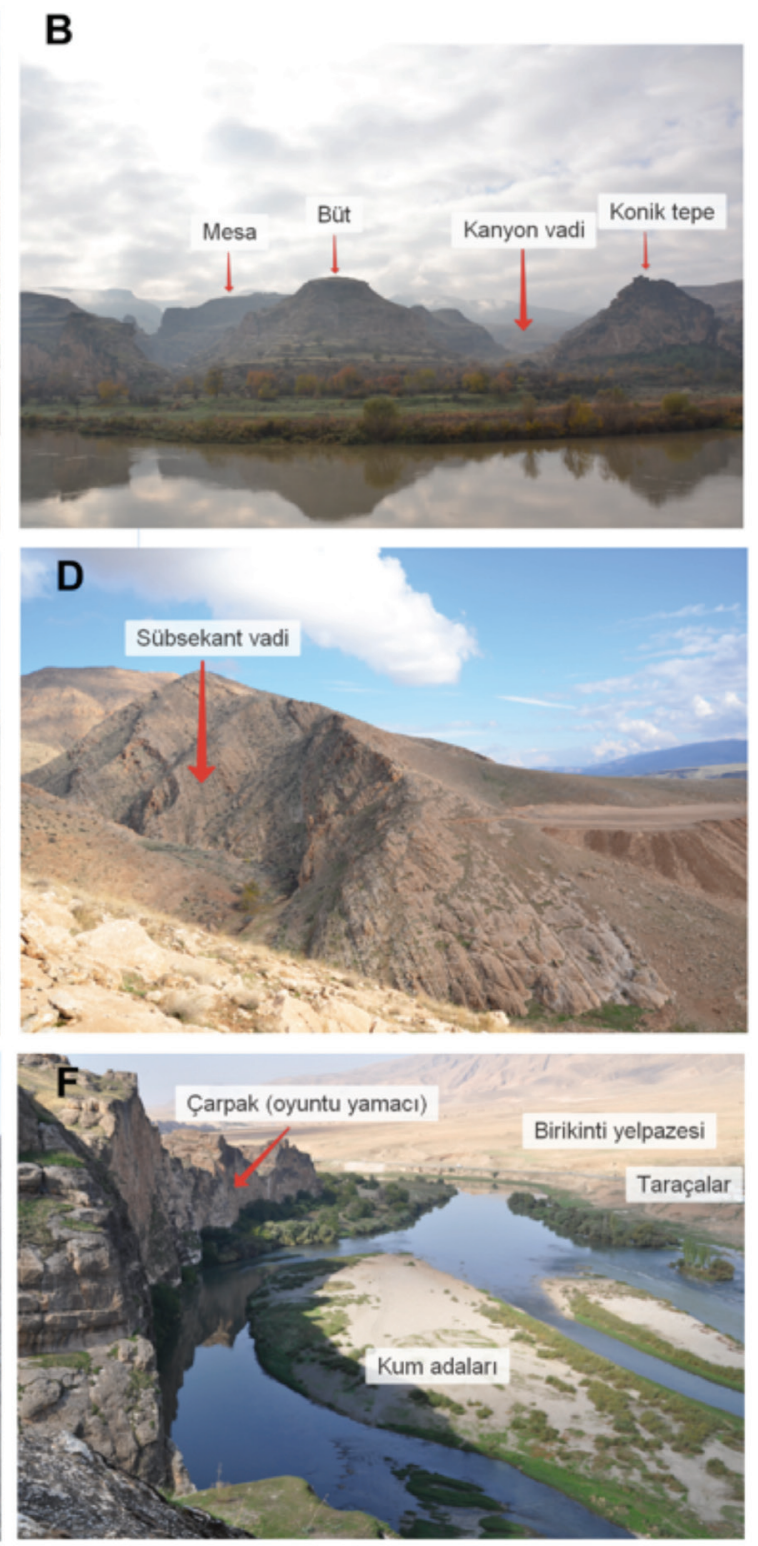

Şekil 4. Hasankeyf çevresinde farklı morfojenetik şekiller: Karstik ve faylı yapılar (A), Yatay yapıya özgü yer şekilleri (B), Monoklinal yapılar (C), Kıvrımlı yapı şekilleri (D-E), Fluviyal yer şekilleri (F).

Figure 4. Different morphogenetic shapes around Hasankeyf: Karstic and faulty structures (A), Horizontal structure-specific ground shapes (B), Monoclinal structures (C), Folded structure shapes (D-E), Fluvial ground shapes $(F)$. 
KÜLTÜREL YERBILIM

AÇISINDAN HASANKEYF VE ÇEVRESİ

Yakın dönemlere kadar yüzlerce kaya oyuğu barınağında insanların yaşadığı Hasankeyf kale yerleşmesi, Dicle Nehri'nin meydana getirdiği oldukça sarp ve dik bir çarpak yamaç gerisinde, kenarları Dicle Nehri'ne kavuşan akarsular tarafından derince yarılmış, korunmaya elverişli mesa şeklindeki bir platform üzerinde kurulmuştur (Karadoğan ve Yıldırım, 2008).-

Yer seçiminde jeolojik ve jeomorfolojik faktörler ön plandadır. Yer seçimini ve yerleşmenin sürekliliğini sağlayan etkenler; litolojik özellikler, savunma kolaylığı, su kaynakları ve su ulaşımı imkânlarıdır. Yerleşmenin konumu ve jeopolitik yapısı, çok eski bir yerleşim merkezi olma ihtimalini kuvvetlendirmektedir (Gabriel, 1940; Tonbul ve Karadoğan, 2001).

Hasankeyf, insan gücüyle kayalara oyulmuş yüzlerce kaya oyuğu mesken ve yerleşme fonksiyonlarından oluşmaktadır. Gerek milattan önce gerekse milattan sonraki çağlarda önemli bir yerleşim merkezi olmuş ve pek çok medeniyeti bünyesinde barındırmıştır. Hasankeyf çevresindeki vadiler de çeşitli dönemlerde yoğun bir şekilde yerleşmeye sahne olmuştur.

Sahip olduğu zengin tarihsel yapıları ve doğal özellikleri nedeniyle Hasankeyf ve yakın çevresi 1981 yılında 2863 Sayılı Kültür ve Tabiat Varlıklarını Koruma Kanununa göre bütünüyle sit alanı ilan edilerek koruma altına alınmıştır. Ilısu Barajı projesi kapsamında ise kurtarma kazı ve restorasyon çalışmaları halen yürütülmektedir. Hasankeyf'in özgün değeri, jeolojik ve jeomorfolojik yapının günün şartlarına uygun olarak akıllıca kullanımından kaynaklanır, öncelikle savunma fonksiyonu ön planda olan bir yerleşmedir. Tektonizma ve güçlü akarsu aşındırması kenarları oldukça dik, sarp, yüksek ve ele geçirilmesi güç yerleşme platformunun oluşmasına neden olmuştur. Öte yandan yerleşme, binlerce nüfusu barındırabilecek kaya oyuğu meskenlerden ve karmaşık yerleşim fonksiyonlarından oluşmaktadır. Bunların en önemlileri yollar, merdivenler, sarnıçlar, Dicle Nehri'ne inen su tünelleri, savunma yapıları ve diğer mimari sosyal ve yönetsel yapılardır (Ergin Y1ldırım, 2006). 

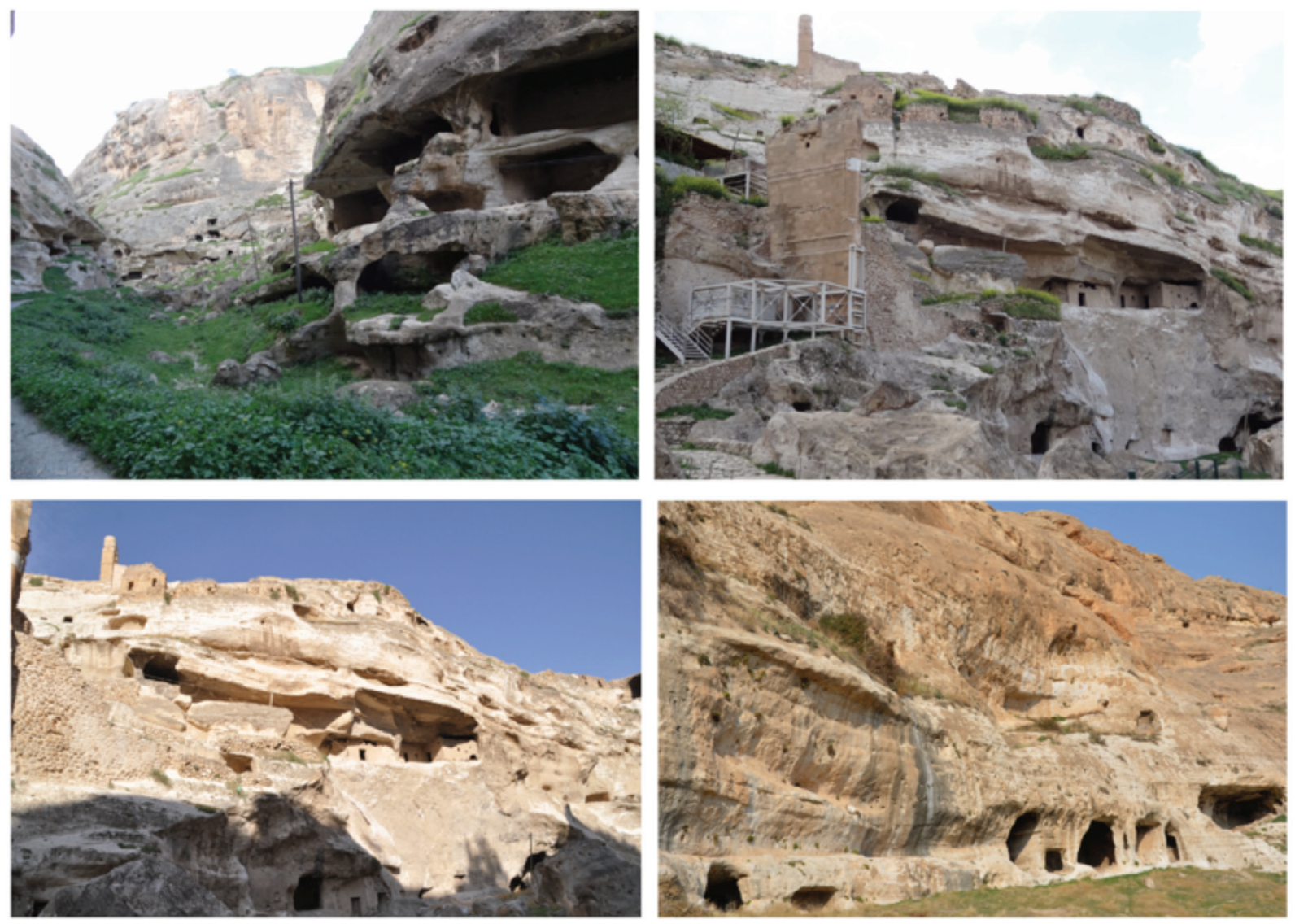

Şekil 5. Hasankeyf kaya meskenleri Hoya Formasyonu'nun üst kesimlerini oluşturan nispeten yataya yakın tabakalı, erime boşluklu, üste doğru evaporit miktarı artan, tebeşirli, travertenimsi karbonatlara oyularak yapılmıştır. Bu kayalar dayanıklı, masif ancak kolay işlenebilir özelliktedir.

Figure 5. Hasankeyf rock houses are made of chalked, similar to travertine carbonates, which are relatively close to bedding, forming a melting zone and increasing the amount of evaporation upward, forming the upper parts of the Hoya Formation. These rocks are durable, massive but easily machinable.

Böylesine karmaşık fakat organize bir kaya kentinin oluşumunda en önemli faktör, jeomorfolojik yapının yanı sıra kuşkusuz kaya özellikleridir. Yerleşme ve çevresinde sadece mesken değil fonksiyonel açıdan oldukça karmaşık ve işlevsel birçok mekan ünitesine, kültürel ve mimari öğeye rastlamak mümkündür (Şekil 6). Yerleşme ve mekansal öğelerinin inşa edildiği birim, sı̆̆ denizel ortamda gelişmiş kireçtaşı ve dolomitlerden oluşan Eosen yaşlı Hoya Formasyonu'nun üst kesimlerini oluşturan nisbeten yataya yakın tabakalı, erime boşluklu, üste doğru evaporit miktarı artan, tebeşirli, travertenimsi karbonatlardır. Bu kayalar dirençli, sağlam, masif ancak kolay işlenebilir özelliktedir. Ayrıca nemli sıcak ve yağışı dönemlerde oluşan traverten ve kalsit kabuklar da kaya kütlelerin dış kesimlerinde koruyucu rol oynamıştır. 

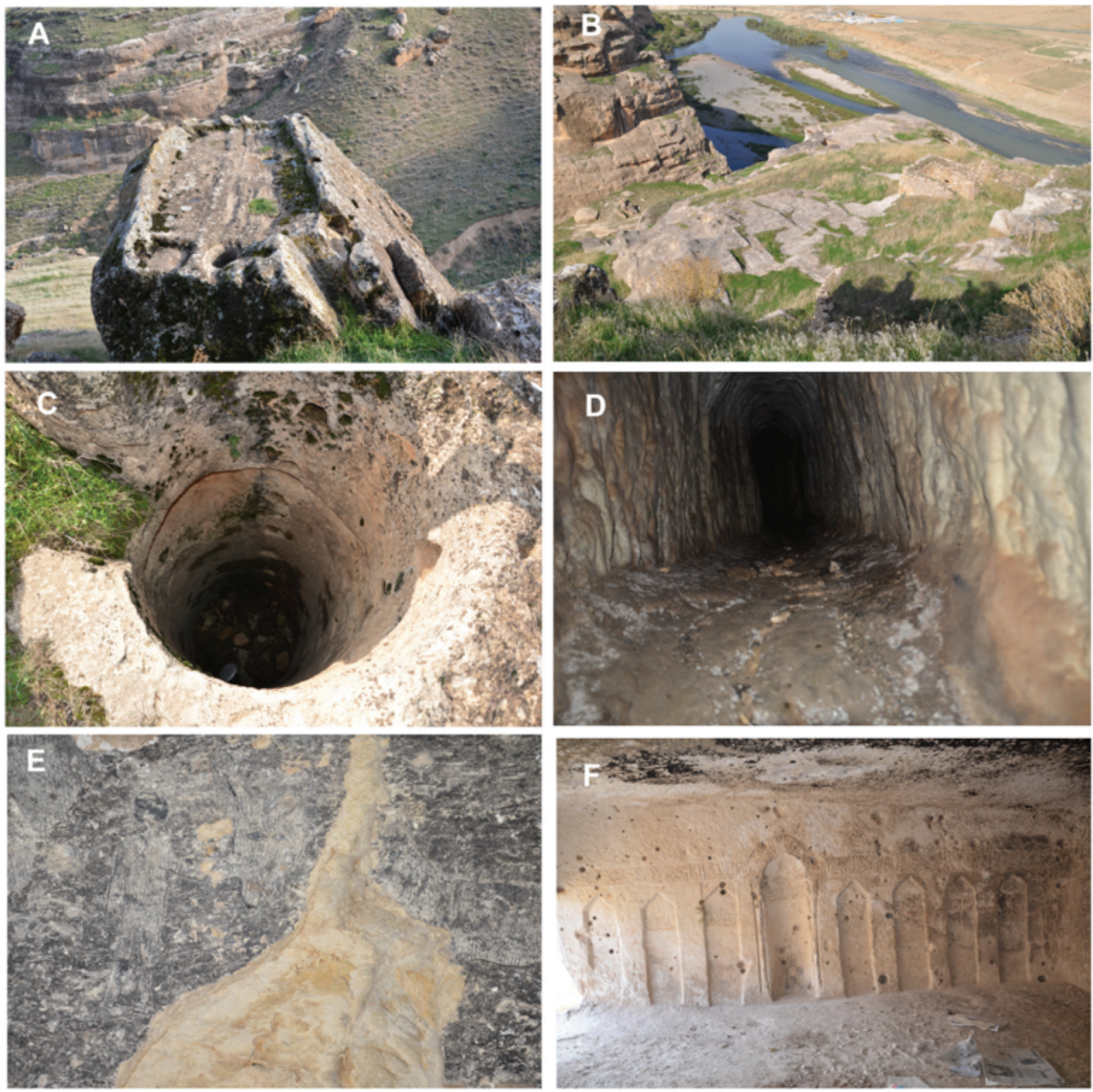

Şekil 6. Hasankeyf ve çevresinde kültürel yerbilim açısından özgün bazı öğeler: kaya kütlelerine işlenmiş mekan üniteleri (A-F), taş ocakları (B), su yapıları, sarnıçlar su tünelleri (C-D), kayalara işlenmiş boyalı figürler (E), dinsel mekanlar (F) (Fotoğraflar: Gülriz Kozbe yürütücülüğündeki "Batman İli Kültür Envanteri" projesinden).

Figure 6. Hasankeyf rock houses are made of chalked, similar to travertine carbonates, which are relatively close to bedding, forming a melting zone and increasing the amount of evaporation upward, forming the upper parts of the Hoya Formation. These rocks are durable, massive but easily machinable (Photos from "Batman Province Culture Inventory" project by Gülriz Kozbe). 


\section{SONUÇLAR}

Birçok uygarlığa ev sahipliği yapmış, tarihi oldukça geçmişe giden ve insanlığın birçok dönemine ait izleri taşıyan tarihi Hasankeyf yerleşmesi ve yakın çevresi, kültürel yerbilim açısından özgün değerlere sahiptir.

Hasankeyf, tarihi öneminin yanı sıra, konumu, yer seçimi, doğal çevrenin akıllıca ve işlevsel kullanımı, adeta bir kaya kentini andıran görkemli görüntüsü, çevresindeki jeolojikjeomorfolojik unsurların zenginliği ve yerleşmenin sürekliliğine etkisi nedeniyle eşsiz bir doğal ve kültürel miras değerimizdir.

$\mathrm{Bu}$ nedenlerden dolay1 Ilısu Baraj1 etkisiyle (Şekil 7) sıkça gündeme gelen Hasankeyf tarihi yerleşmesi sadece yerleşme çekirdeği olarak değil, çevresiyle birlikte özgün bir kültürel jeolojik miras değeri olarak ele alınması, korunması ve değerlendirilmesi gerekir. Ayrıca kazı, kurtarma, ve belgeleme çalışmalarının sadece kale bölümünde değil, tüm yakın çevrede özellikle Ilısu Barajı gölü altında kalma riski taşıyan yerlerde yapılması gerekir.

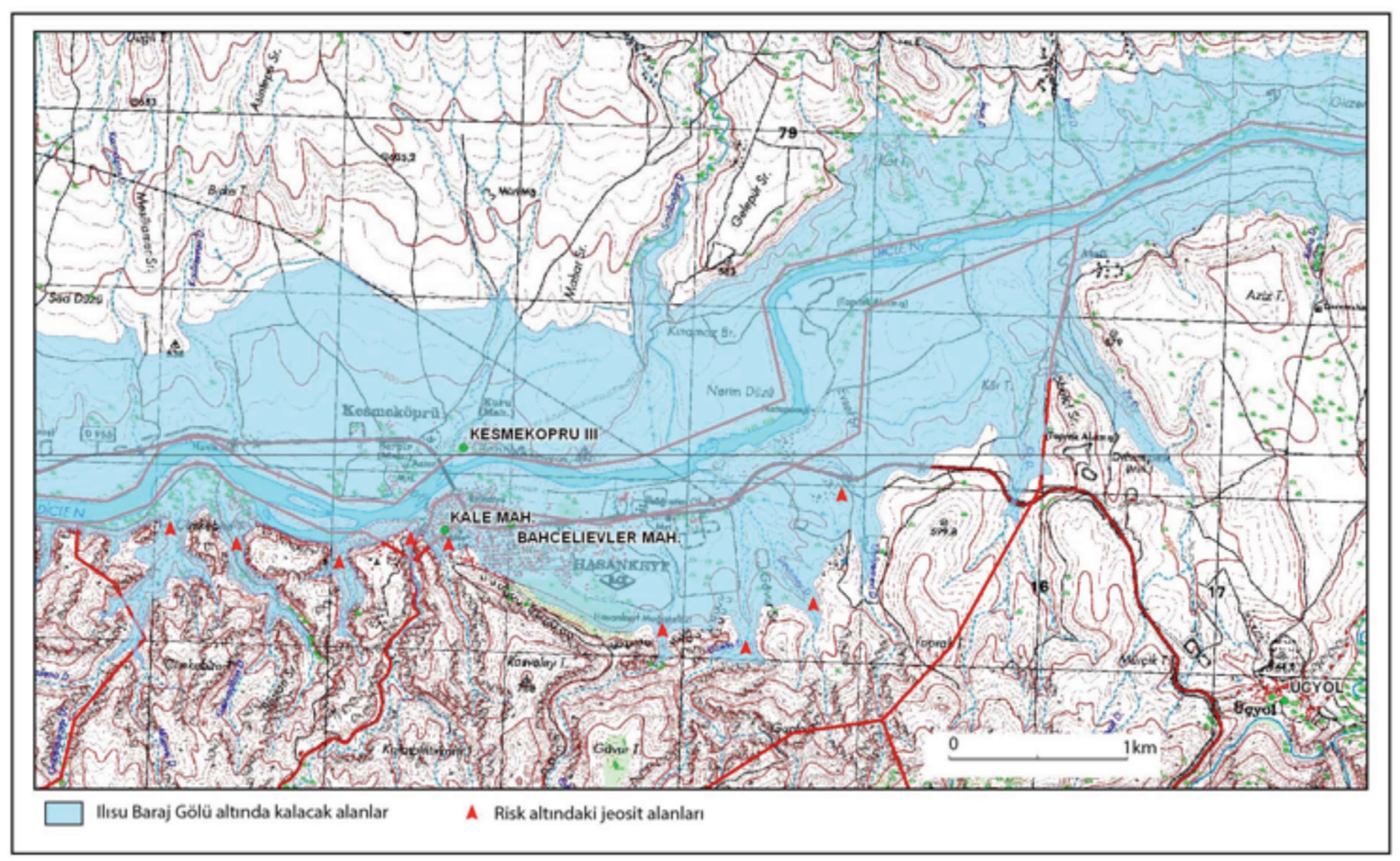

Şekil 7. Hasankeyf yakın çevresinde risk altındaki jeosit alanları

Figure 7. Geosite areas under risk in the vicinity of Hasankeyf.

\section{EXTENDED SUMMARY}

Although Hasankeyf, located by the Tigris river $35 \mathrm{~km}$ south-eastern Batman, was the centre of science and culture of the region with educational institutions such as madrasas, observatory, health centres in its past, it is now a historical settlement place which lost its importance because transportations ways changed their routes and commercial centres changed their places. Hasankeyf, whose edges reach to the coast of the 
Tigris river, which was built on the planes in the shape of steps convenient for protection deeply cut by rivers, which consists of hundreds of caves and settlement functions curved into the rocks with human power. Hasankeyf has been an important settlement place both before Christ and after Christ ages and has cradled many civilizations.

Hasankeyf and its nearby vicinity were declared as site area and taken under protection by the Ministry of Culture and Tourism according to Cultural and Natural Assets Protection Law dated 1981 and numbered 2863 due to rich historical structures and natural features. The authentic value of Hasankeyf stems from the fact that the geological and geomorphological structure was used wisely in accordance with the conditions of those days. Hasankeyf is initially a settlement place whose defence function is in the foreground. Tectonism and strong river erosion have led to formation of a settlement platform whose edges are very steep, jagged and high and whose seizure is very difficult. On the other hand, the settlement consists of man-made rock hollow shelters and complex settlement functions which can accommodate a population of thousands (streets, stairs, rainwater reservoirs, water tunnels going down to the Tigris river, defence structures and other architectural social and governmental buildings). The most important factor in existence of such a complex and organized rock city is, without doubt, properties of the rock besides geomorphological structure. The unit, where houses are curved and sheltered city is constructed, is of carbonates relatively horizontal layered, melting pore, the evaporitic amount of which increases towards upper part, chalky, travertine like carbonates which make the upper part of Eocene Hoya Formation comprising of limestones and dolomites occurring in shallow marine environment. These rocks are resistant, strong and massive, while they have properties to be easily worked on.

In addition to historical importance, it is essential that Hasankeyf should be handled and evaluated as a cultural and geologic heritage because of its location, selection of its place, usage of the natural environment wisely, its magnificent appearance resembling to a rocky city, the richness of geological and geomorphological structures around it and its effect on lasting settlement.

\section{DEĞİNILEN BELGELER}

Bahtiyar, İ., Siyako, M. ve Kaya, M., 2015. Batman çevresi Geç Mestrihtiyen- Paleosen dönemi stratigrafisi. Türkiye 20. Uluslararası Petrol ve Doğalgaz Kongresi Özler ve Bildiriler Kitab1, 209-211.

Bolgi, T., 1961. V. Petrol Bölgesi seksiyon ölçmeleri AR/TPO/261 no'lu saha ile Reşan-Dodan arası batısındaki sahanın strüktürel etüdleri: TPAO Arama Grubu, Rapor no. 162, 52s.

Ergin Yıldırım, B., 2006. Hasankeyf İlçe Merkezinin Beşeri ve Ekonomik Coğrafyası, Fırat Üniversitesi, Sosyal Bilimler Enstitüsü, Coğrafya Anabilim Dalı, (Yayımlanmamış Yüksek Lisan Tezi), Elazı̆̆.

Gabriel A., 1940. Voyages Archologiue Dans la Turquie Orientole, Paris, 55.

Karadoğan, S., Yıldırım, A., 2008. MardinMidyat Platosunun Ekoturizm Açısından değerlendirilmesi. Ankara üniversitesi Türkiye coğrafyası Araştırma ve uygulama Merkezi "V. Ulusal Coğrafya Sempozyumu 16-17 Ekim 2008" ANKARA.

Koaster, E. A., 1963. Petroleum geology of District V, Turkey with special reference to license no. 649 
of Aladdin Middle East Ltd (AME Report): Petrol İşleri Genel Müdürlüğü Teknik Arşivi, Kutu no 125, Rapor no 4, $22 \mathrm{~s}$.

Kozbe G., (Yürütücü, Editör), Batman İli Kültür Envanteri, T.C. Batman Valiliği ve Batman İl Kültür ve Turizm Müd. Projesi, 2014-2017

Maxon, J.H., 1937. Reconnaissance geplogy, oil possibilites and mineral resources of Southeastern Turkey: MTA Derleme No: 680, 80 s.

Perinçek, D., 1978. V-VI-IX. Bölge (Güneydoğu Anadolu otokton allokton birimler) jeoloji sembolleri: TPAO Arama Grubu Rapor no. 6657.

Siyako, M., Bahtiyar, İ., Özdoğan, T., Açıkbaş, İ. ve Kaya, Ö.Ç., 2013. Batman çevresinde mostra veren birimlerin stratigrafisi. TPAO Arama Dairesi Başkanlığı Arşivi, yayınlanmamış teknik rapor, 5463, $152 \mathrm{~s}$.

Siyako, M., Şeker, H., Bahtiyar, İ., Özdemir, İ., Kılınç, S.F., Arslan, D., Karaçay, A., Özsoy, S. ve İşdiken, B., 2015. Batman, Beşiri, Kurtalan, Raman ve Gercüş civarının jeolojisi ve hidrokarbon olanakları. TPAO Arama Dairesi Başkanlığı Arşivi, yayınlanmamış teknik rapor, 5546, $132 \mathrm{~s}$.
Tonbul, S., Karadoğan, S., 2001. Dicle Havzasındaki Doğal Çevre ve Beşeri Özellikler İle Arkeolojik Değerlerin, Bölge Paleo-Coğrafik ve PaleoKültürel Koşulların Belirlenmesindeki Rolü ve Bugünkü Durum. Türkiye Anıt Çevre ve Turizm Vakfi 25. Yıl Armağan Kitabı, s.341-352.

Yıldırım, A., Karadoğan, S., 2005. Raman-Gercüş Antiklinalleri Arasında Dicle Vadisinin Jeomorfolojisi. Ulusal Coğrafya Kongresi, Türk Coğrafya Kurumu-İstanbul Üniv, 29-30 Eylül 2005, 421-432, İstanbul.

Yıldırım, A., Karadoğan S., 2011. Raman Dağları Güneyinde (Dicle Vadisi) Morfometrik ve Morfotektonik Analizler. D.Ü.Eğitim Fakültesi Dergisi, Say1:16, S. 154-166, Diyarbakır

$\begin{array}{ll}\text { Makale Geliş Tarihi } & : \text { 18 Haziran } 2016 \\ \text { Kabul Tarihi } & : \text { Ekim } 2016 \\ \text { Received } & : \text { 18 June 2016 } \\ \text { Accepted } & : \text { 19 October 2016 }\end{array}$

